Article

\title{
Using Microlending to Achieve SDG 2: A Qualitative Exploration of the Nutrition-Related Impacts of Microlending Participation in Manila, Philippines
}

\author{
Michelle U. Grocke ${ }^{1, *}$, Timothy Light ${ }^{2}$, Elijah Karl Collado ${ }^{3}$ \\ 1 Department of Health and Human Development, Montana State University, \\ Bozeman, MT 59717, USA \\ 2 Department of Sociology, Social Work and Anthropology, Utah State University, \\ Logan, UT 84322, USA \\ 3 OYO Technology and Hospitality, Cainta, 1800, Philippines \\ * Correspondence: Michelle U. Grocke, Email: michelle.grocke@montana.edu; \\ Tel.: +1-406-994-4711.
}

\begin{abstract}
Background: The recent rise of the double burden of malnutrition (i.e., the coexistence of underweight and overweight) in the Philippines presents a significant challenge to achieving numerous agreed-upon Sustainable Development Goals (SDGs). To combat the rising trends of both forms of malnutrition, this research assesses whether there are positive nutritionrelated impacts from participation in a microlending program, and also seeks to determine whether microlending participants would be receptive to receiving nutrition promotion education as a component of the microlending model. If so, then microlending could serve as an effective information dissemination platform to increase the likelihood that participants will make nutritious food choices as they acquire more disposable income, thereby keeping both malnutrition rates and the subsequent risk of diet-related non-communicable diseases (NCDs) at bay.
\end{abstract}

Methods: Ethnographic fieldwork in 15 distinct urban neighborhoods in Manila, Philippines was conducted between May and August 2017. 24-h diet recalls and semi-structured interviews were utilized $(N=93)$ to

\section{Open Access}

Received: 30 September 2019

Accepted: 31 January 2020

Published: 05 February 2020

Copyright (C 2020 by the author(s). Licensee Hapres, London, United Kingdom. This is an open access article distributed under the terms and conditions of Creative Commons Attribution 4.0 International License. determine whether and how participants' food procurement decisions and macro- and micronutrient intake shifted throughout their participation in a microlending program.

Results: Interview data illustrate that participants' food procurement options and their sense of self-worth and empowerment increased the longer they were involved in the microlending program. However, the nutritional outcomes are more nuanced; while participants who had been in the program longer showed higher levels of micronutrient intake, they also consumed elevated levels of prestige items high in sugar and/or salt. Given that participants reported high levels of uncertainty surrounding nutritional information, more education is needed to reverse this trend 
and decrease the risk of malnutrition development and the associated adverse health outcomes.

Conclusions: Microlending platforms may be a viable avenue for disseminating nutrition-related information. However, our data indicate that participants may only be receptive to this information after at least two years of participation because, prior to that, participants are too concerned with income generation, housing stability and their family's education to fully absorb the information.

KEYWORDS: microlending; double burden of malnutrition; diet-related non communicable diseases; ethnography; 24-h diet recall; Philippines

\section{ABBREVIATIONS}

SDGs, sustainable development goals; NCDs, non-communicable diseases; WHO, World Health Organization; CDC, Center for Disease Control and Prevention; MSG, Monosodium Glutamate

\section{INTRODUCTION}

In 2015, all United Nations member states agreed upon the 17 sustainable development goals (SDGs), and committed to working together to achieve them by the year 2030 [1]. SDG 2 is to "end hunger, achieve food security and improved nutrition and promote sustainable agriculture". To achieve this particular goal, five desired outcomes were created, the first of which reads "by 2030, end hunger and ensure access by all people, in particular the poor and people in vulnerable situations, including infants, to safe, nutritious and sufficient food all year round" (emphasis added by authors) [2].

Two thirds of undernourished people worldwide live in two regions, Southern Asia (277 million) and Sub-Saharan Africa (237 million) [2]. The Philippines, specifically, faces a double burden of malnutrition, which is characterized by the coexistence of undernutrition along with overnutrition (i.e., being overweight and obese, or with diet-related noncommunicable diseases (NCDs)). This double burden is reflected in the following statistics - as of 2015, the national prevalence of under-five stunting is $33.4 \%$, which is higher than the developing country average of $25 \%$. Within the same time frame (i.e., 2000 to 2016), the prevalence of overweight individuals among Filipino adults increased from $21.6 \%$ to $28.9 \%$ for females and from $17.4 \%$ to $26.1 \%$ for males [3,4].

In the presence of a double burden of malnutrition, not only do underweight individuals and overweight individuals coexist, but both the epidemiology and the evidence support the facts that (1) undernutrition early in life may predispose an individual to being overweight and to developing diet-related NCDs (i.e., cardiovascular disease, diabetes and cancer) later in life [5], and (2) being overweight in mothers is associated with being overweight, obesity, and the development of additional 
negative health outcomes in their children [6,7]. In addition to predisposition, an unhealthy diet as an adult is one of the primary risk factors for numerous NCDs: for example, 1.56 million annual deaths from cardiovascular causes have been attributed to excess salt/sodium intake [8], increased consumption of ultra-processed foods has been linked to increased risk of cardiovascular disease, coronary heart disease, and cerebrovascular disease [9], while increased consumption of fruits and vegetables as a single intervention has been cited to have favorable effects on cardiovascular disease prevention [10].

Moreover, individuals living in low- and middle-income countries are at an even higher risk, since the modifiable risk factors (i.e., exposure to tobacco use, physical inactivity, unhealthy diets, harmful use of alcohol) tend to be higher. These risk factors also increase at a higher rate among low-income populations because of socio-economic determinants such as population growth, rapid and unplanned urbanization, marketing and trade of health-harming products, and inadequacies in public health policies [11,12].

The aforementioned data foregrounds the importance of investing time and effort in ensuring that adults, especially women living in resourcepoor environments, have access to both nutritious and sufficient food (SDG 2), particularly given the associations between poor-diet and risk for NCDs, which now account for $71 \%$ of deaths globally. In addition to the mortality figures, NCDs have been cited as presenting a significant challenge to achieving numerous other internationally agreed upon SDGs [13].

In response to this challenge, the World Health Organization (WHO) partnered with the leaders of the UN General Assembly in 2011 to establish 12 initiatives (the following four of which are diet-focused and specifically relate to SDG 2) [12]:

a. Adopt national policies to reduce population salt/sodium consumption;

b. Adopt national policies that limit saturated fatty acids and virtually eliminate industrially produced trans fatty acids in the food supply;

c. Follow the WHO set of recommendations on marketing of foods and non-alcoholic beverages to children;

d. Legislation/regulations fully implementing the International Code of Marketing of Breast-milk Substitutes.

As of 2017, only the last of the aforementioned dietary initiatives has been achieved, while there has been limited progress made on the others [12]. However, there has been a general reduction of tobacco and alcohol consumption [12], in addition to progress made by a specific WHO/CDC campaign aimed at delivering targeted services to people at risk for heart attacks, strokes, hypertension and other cardiovascular conditions [14]. Although a few such programs are now underway, according to the most recent Filipino National Nutrition and Health Surveys [15], not nearly enough is being done in terms of reducing the diet-related risk factors for NCDs, and ensuring that all individuals have access to not only sufficient 
(i.e., caloric intake) but nutritious (i.e., adequate macro- and micronutrients) food (SDG 2).

In thinking through what existing infrastructure could be utilized to help achieve these goals, the authors turned to microlending. Globally, the impact of microlending programs has been immense. In 2016, it was reported that microlending organizations were serving 123 million people, with a total loan portfolio of $\$ 102$ billion [16]. The Southern Asia microloan market accounts for $60 \%$ of all global borrowers and consistently has the highest growth rate in terms of loans [16]. Although microlending has recently received some negative feedback [17,18], in numerous contexts it has been shown to diversify household income and to alleviate poverty [19], to have positive impacts on participants' nutritional status and food security [20,21], and to positively impact the health of participants' children [22]. Furthermore, numerous microlending organizations have recently begun to incorporate health education services into their models, the results of which have been positive in terms of expanding health education coverage and lowering service delivery costs [23], assisting communities in strengthening their malaria initiatives [24], and helping microlending participants engaging in safer sexual behavior [25] and reduced rates of intimate partner violence [26].

The goal of this study is to contribute to this area of scholarship by assessing whether participation in microlending programs results in different dietary behavior by participants, and if so, how long it takes for the impacts of this behavior change to be realized. Of the few studies that have tested health and nutritional outcomes for microlending participants, most have relied heavily on assessing these outcomes through the collection of biometric data and have not included a thorough nutritional assessment of food consumption patterns [20,27,28]. Numerous scholars have simultaneously concluded that although microfinance organizations are a promising method for disseminating health-related services to hard to reach populations, they are being underutilized in this regard [29]. By including an analysis of microlending participants' food consumption and nutrient intake patterns, our overall aim is to assess whether microlending institutions could also be utilized as effective intervention platforms for disseminating nutritional information, particularly in low-middle income countries where more progress needs to be made to achieve SDG 2 and to keep the double burden of malnutrition at bay.

\section{METHODS}

We conducted four months of mixed method, ethnographic fieldwork between May and August 2017 in 15 distinct neighborhoods in Manila, Philippines. All research participants $(N=93)$ were actively involved in the Mentors International microlending program, a non-profit organization started in 1990. This microlending program provides individuals with tools (i.e., start-up capital and technical assistance training) to help them to grow and successfully run their own businesses. In order to qualify for 
the program, individuals must have already been in business for at least one year, are required to submit a feasible business plan, and are required to have access to at least 3000-5000 pesos (about 60-100 USD) of start-up capital. Interested participants are eligible to apply for a group business loan, and then are held accountable to other group members for repayment.

In 2017, an average of 150 new clients per month (99\% of whom were women) joined Pasig and Antipolo, two urban branches of the Mentors International microlending program in the Philippines (Both Pasig and Antipolo are cities located in Metro-Manila. The Pasig branch is the headquarters of Mentors Philippines, and therefore, the local staff recommended it as one of our two research locations). Based on these intake figures, we utilized a web-based randomizer to select 94 total participants for our research study. After being selected, participants were contacted by our research translator (although our translator was not an employee of Mentors Philippines at the time of data collection, he was a past staff member who had already built a strong rapport with the participants, which likely played a role in participants' willingness to participate in the research) and were asked if they would be willing to participate. Of these 94, 47 were new to the Mentors program (termed Group 1a; $N=46$, response rate $=98 \%$ ) whereas 47 had been in the program for two or more years (termed Group 2; $N=47$, response rate $=100 \%$ ). Three months after our initial data collection, we contacted all Group 1a participants for a follow-up interview. 24 of the original 46 participants agreed, resulting in a response rate of 52\% (termed Group 1b; $N=24)$. Research participation incentives were not offered.

In order to assess whether and how participation in the Mentors program may have been impacting participants' nutrition outcomes, we conducted a 24-h diet recall and a semi-structured interview with all research participants. These were conducted in participants' homes and/or place of work, with the assistance of a local translator, and lasted roughly one hour.

The 24-h diet recall is a validated dietary assessment tool in which participants recall the type, quantity and preparation method of all food and drink that they consumed in the previous 24-h period [30-32]. Each 24-h diet recall began with the researcher asking, "What was the first thing you ate or drank when you woke up yesterday morning?” The researcher then continued to record responses and ask follow-up questions to assist participants in recalling consumed food and beverages until all that was consumed during the last 24-h period was recorded. In order to assist participants in recalling and determining the serving size of each food consumed, a validated serving size reference image was utilized [33].

Though the data collected in this study are largely qualitative, the 24-h dietary recall data provided us with a detailed understanding of the type, quantity, and frequency of the foods that individuals were consuming. We entered the 24-h diet recall data into The Food Processor Nutrition and 
Fitness Software, a validated product designed by ESHA Research [34] that has been used in many cross-cultural diet-related research studies [35-37]. This nutrient analysis software utilizes multiple verified nutrient databases to allow users to input the type and quantity of food/beverage that participants' consumed and to be able to subsequently view the amount of both macro- and micro-nutrients ingested. We relied on this software to both process our 24-h diet recall data as well as to calculate the average daily macro-nutrients (i.e., grams of protein) and micro-nutrients (i.e., Vitamin A) consumed by each group (Group 1a, Group 1b and Group 2). To provide context to this dietary intake data, we also conducted semi-structured interviews with each research participant (see the Supplemental Materials section for the semi-structured interview and 24-h diet recall documents (including their Tagalog translations)). Interview data also helped us to determine if and how individuals' dietary habits, access to food, and food preferences had changed since the beginning of their participation with the Mentors microlending program.

This mixed-methods study design allowed us (a) to assess whether there were differences in food consumption patterns and nutrient intake between those who had just started the microlending program and those who had been involved in it for two or more years (Group 1a compared to Group 2), and (b) to track the group that just started participating in the microlending program to assess whether they experienced any sort of change in food consumption or nutritional intake within the first three months (Group 1a compared to Group 1b).

Informed consent was obtained from all participants before conducting 24-h diet recalls and interviews. Participation in this study was completely voluntary and in no way affected participants standing in the microlending program. This research received Institutional Review Board approval from Utah State University (IRB \#8410).

\section{RESULTS}

According to interview data, Mentors International microlending participants reported experiencing several benefits as a consequence of their participating in the program. According to one 28-year-old woman participant, "After I received the loan, we started to build our business and our house. After, we were able to buy everything we wanted." Numerous other microlending participants mirrored the sentiment of this woman, remarking that they are now able to support their children through secondary school and even college after participating (SDG 4), while others were able to find new housing and/or to afford to make improvements to their homes as a result (SDG 11). Of the participants who indicated that they had experienced these types of benefits, all of them additionally stated that they now have more agency and flexibility in terms of their food consumption patterns (SDG 2, 3). 


\section{Local Food Culture}

Our interview data indicate that the typical diet of microlending participants in Manila (it must be noted that this "local food culture" description is representative of microlending participants in Manila, and not necessarily of Filipinos in general or those who live in more rural areas) consists of numerous dishes made from white flour, protein and vegetable dishes that are often fried and cooked with sauces high in sodium, and a variety of processed, packaged foods that supplement the main meals during snack time (Table 1).

Breakfast often consists of white-flour rolls and coffee. Main meals, such as lunch and dinner, often have a disproportionately high ratio of white rice to ulam (i.e., the main dish, which is usually a protein or vegetable), with roughly 2 cups of rice being served with every $1 / 4$ cup of ulam. Additionally, ulam is frequently high in sodium, as it is often prepared with three different sodium sources: soy-sauce, salt, and MSG. Sawsawan (i.e., dipping sauces such as bagoong (concentrated fish paste), ketchup, chili sauce) are also frequently incorporated into meals or as an accompaniment to snacks. It is also very typical to have a merianda (midafternoon snack) of fried foods (i.e., fried bananas, fried hard boiled eggs) or processed foods high in sugar (e.g., soda pop). According to one interview, many Filipino families also consider the addition of soft drinks to a meal to be a cultural staple. This is evidenced by the fact that this particular interviewee recalled his grandmother saying, "a meal is not complete without a bottle of Coca Cola". He justified this decision, particularly for resource poor households who do not have access to a refrigerator, by stating that a store-bought soft drink may be the only cold reprieve from a hot day.

Table 1. A typical diet.

\begin{tabular}{cr}
\hline Meal & Food Typically Consumed by Microlending Participants \\
\hline Breakfast & Instant coffee (packaged with cream and sugar) and white rolls (pandesal) \\
Lunch & white rice, pork or chicken cooked in soy sauce, salt, MSG, garlic and onion (adobo) \\
Mid- & white bread, saltine crackers, deep fat fried caramelized banana (banana cue), \\
afternoon & caramelized banana wrapped in a thin tortilla (turon), or deep fat fried hard boiled \\
snack & eggs ( $k$ wek kwek), eaten with coffee, instant juice, or soft drinks \\
Dinner & leftovers from lunch (often w/soft drinks) \\
\hline
\end{tabular}

When we asked participants how exactly they thought their food consumption agency and flexibility had increased, many participants in Group 2 (i.e., those who have been with the program for two or more years) referenced the fact that they now have both the time and money to be able to shop at the larger grocery stores located throughout metro Manila. 
According to our nutritional outcomes data, this ability to diversify food procurement options has allowed participants both to increase their caloric intake as well as to increase their diet diversity, both signs of improvement towards achieving SDG 2.

\section{Food Sourcing}

When asked, "Where do you buy most of your food?" participants responded in a variety of ways. Many responded that it is a common morning routine for them to stop by the neighborhood bakery for a couple of white rolls followed by a trip to the small neighborhood convenience store for some instant coffee. Lunch and dinner were either cooked at home or eaten at a variety of different local cantinas (restaurants) depending on how far the participant had to travel to and from their business. Our interview data elucidated that where participants sourced their food very much aligned with their economic stability, and thus, in many instances, was related to how long they had been in the microlending program.

\section{New microlending participants: sari saris}

Those participants who had recently received a microloan stated that they were experiencing high levels of stress. Not only were they overwhelmed by the challenges of starting a business, but they never felt as though they had enough time in the day to complete necessary tasks. Because this group felt constantly overwhelmed and pressed for time, they shopped mainly at the sari sari stores because they were conveniently located around the corner (Figure 1).

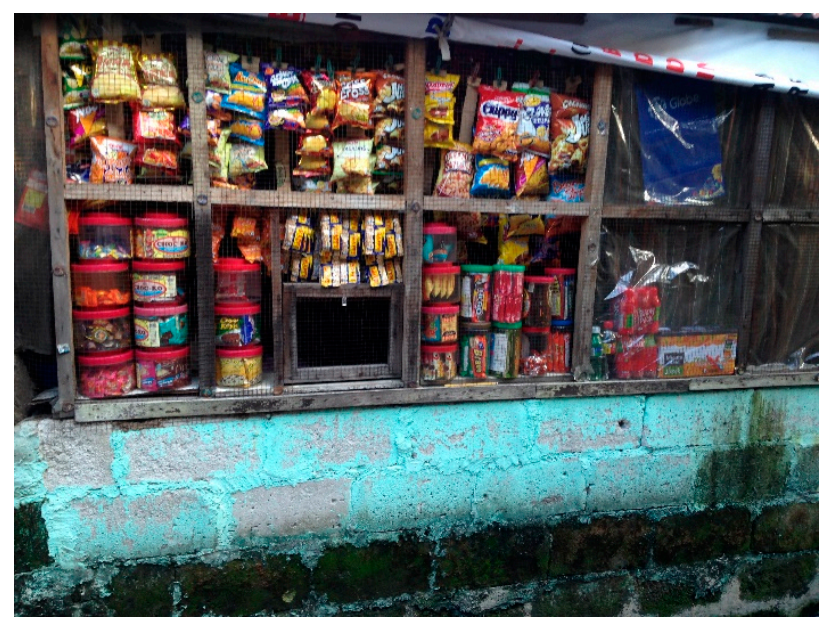

Figure 1. A typical sari sari store. These are usually run out of the front room of an individual's home and are frequented regularly by members of the surrounding community.

Although some sari saris also carry a small amount of garlic, onion, tomato or eggplant (which are ingredients frequently used in Filipino cooking), the lack of supply coupled with the high price makes it difficult for consumers to purchase those items in sufficient quantities. Instead, 
items like instant coffee and those high in sugar and salt (i.e., soft drinks, crackers, instant noodles, sardines, MSG, and seasoning cubes) were the popular food items purchased at these stores (Figure 2). Although some sari sari items may seem inexpensive (for example, a 1.5-liter bottle of soda could be purchased for the equivalent of 0.27 USD), these prices per item are much higher than if purchased in bulk in larger stores.

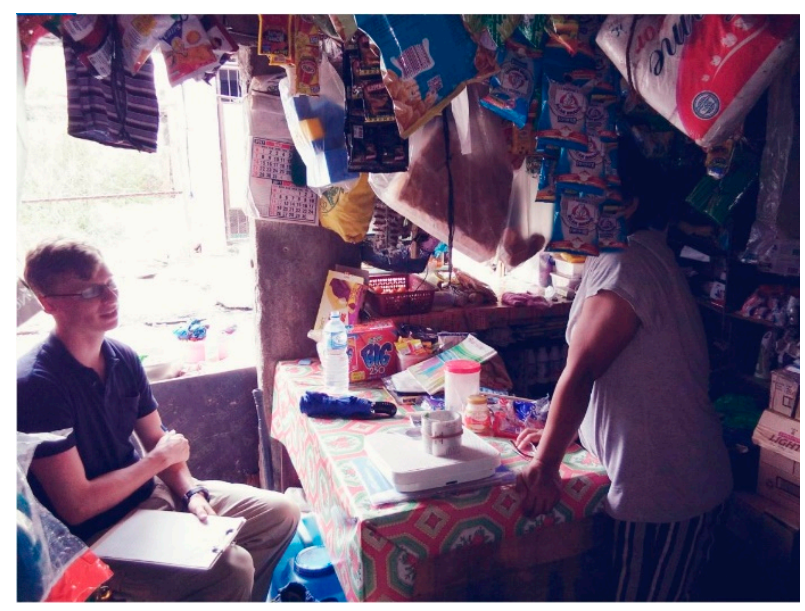

Figure 2. TL interviews a participant in her small, crowded sari sari store.

Ethnographic data indicate that participants new to the microlending program expressed that they lacked the time and do not have sufficient economic means to shop at larger markets and grocery stores (where they could buy more nutritious foods and could buy these foods in bulk). These individuals were working hard to get their businesses off the ground, so every minute of their time was precious. In order to shop at a larger market or grocery store, they not only had to spend money for transportation, but they were required to take valuable time out of their busy schedules that they simply felt they could not afford. The following conversation that TL had with participant $M$ is reflective of this trend.

TL: Why do you shop primarily at the sari sari?

M: "I have no time to go to the market. My time is precious because I have a lot of clients.”

TL: If you had more time, would you still shop at sari sari?

M: "No, I would go to the palengke!"

TL: Why?

M: "Less price. Sometimes you can get things in bundles."

Though buying fresh produce and meat from the market was cheaper and more nutritious, because of time constraints participants felt that their only option was to buy the majority of their food from sari sari stores. Unfortunately, sari sari stores only contain foods that are both expensive in the long run and low in nutritional value. Food procurement patterns, such as the aforementioned dilemma that new microloan recipients tend to face, create mini food deserts and, ultimately, perpetuate the poverty 
cycle because participants are spending a large portion of their income on food.

\section{At least two years of participation: palengke markets}

According to interview data, as clients progressed in the Mentors microlending program, their food procurement patterns changed from shopping primarily at sari saris to shopping at the local market (palengke). One participant who was able to shop at the palengke after being with the Mentors program for a mere two months, stated, "before I had the loan, I only had noodles and canned goods like sardines...but now I buy pork and other goods from the palengke. Now I can buy whatever foods that we may want.” Palengke markets are traditional, usually open-air markets that consist of a multitude of vendors that sell food items as well as a variety of other commodities (Figure 3).

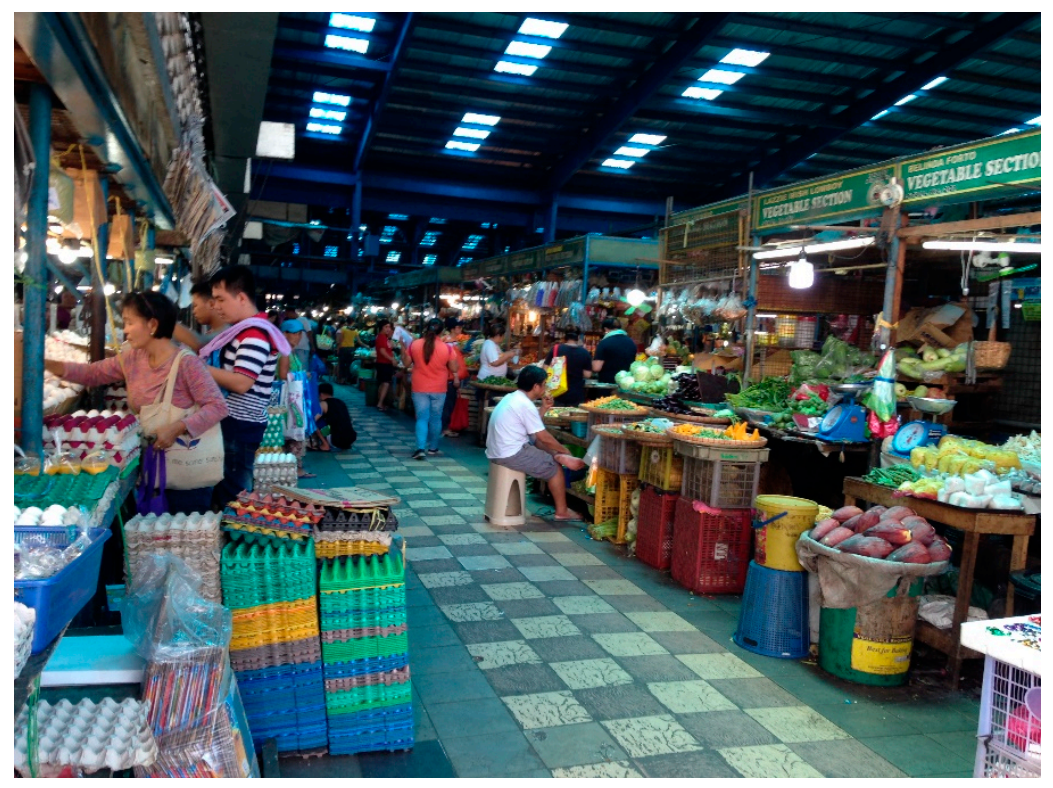

Figure 3. View of the vegetable quarter from the south end of the Pasig City Palengke, one of the largest markets in Metro Manila. Meat, clothing, household goods and a variety of other commodities are sold here. Pasig Palengke is also popular for concerts and social gatherings.

The palengke provides individuals with the opportunity to purchase nutritious foods at lower prices than the sari saris. They are also much larger and therefore carry a greater variety of foods. Therefore, when participants are able to shop primarily at the palengke, they have an increased ability to purchase foods that constitute a well-rounded diet. However, this food source is also accompanied by some nutritional concerns because some palengke foods are stored in suboptimal hygienic conditions. Meat vendors, for example, begin displaying their products early in the morning (3-4 am) and continue to sell them until about around 5-6 pm. With average temperatures resting around 80 degrees Fahrenheit (28 degrees Celsius) and humidity ranging from $75 \%$ to $85 \%$, food-borne 
illness is a common concern (Figure 4). By $5 \mathrm{pm}$, the smell of rotting meat perforates nearly the entire palegnke.

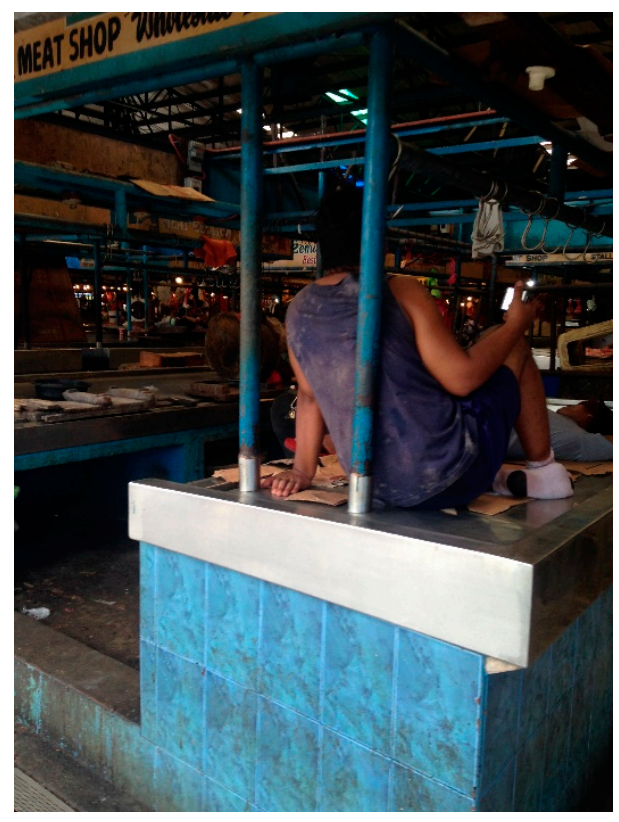

Figure 4. Meat vendors enjoying a lunchtime nap next to the meat products for sale at the palengke. Many locals avoid buying meat at the end of the day because they know that it has been unrefrigerated in tropical weather for $12-16 \mathrm{~h}$ by evening.

\section{Long-term participation and business success: grocery stores}

The last group consists of the longer-term Mentors participants who have managed to build a stable business that provides them with a steady income. According to interview data, these individuals choose to shop at both the palengke and the grocery stores (the two most common being Robinsons and Pure Gold) (Figure 5).

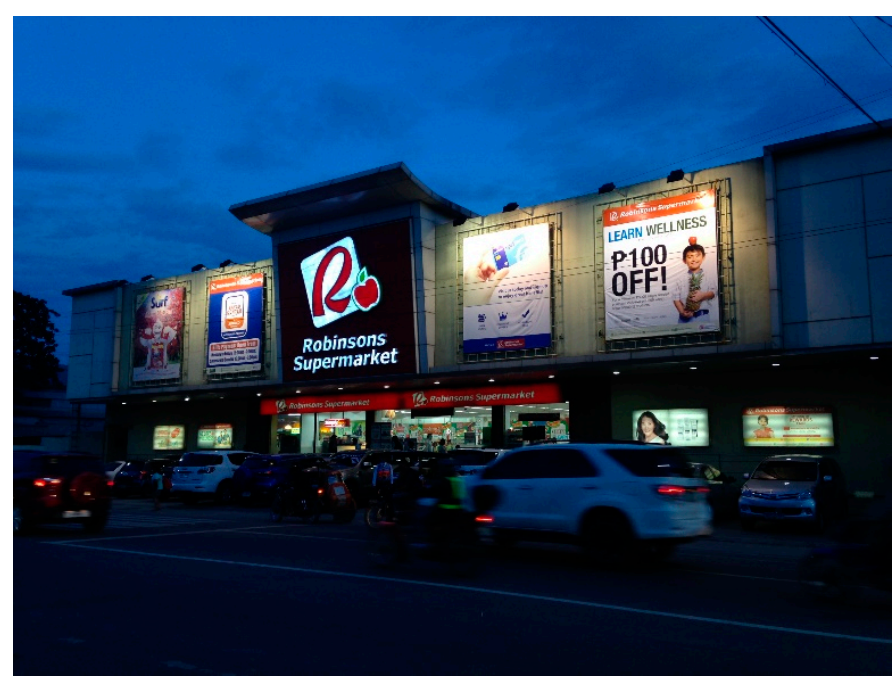

Figure 5. Robinsons Supermarket. This grocery store is similar to grocery stores found in high-income countries. 
The microlending participants who are able to shop at the grocery stores stated that they try to buy their meat from the grocery store because they feel that it is a hygienically safer option. However, participants typically continue to purchase their vegetables from the palengke because they are usually cheaper and fresher than the grocery store vegetables. In addition to being able to exercise their agency in terms of where they buy their groceries, participants reported feeling a sense of empowerment and self-worth when they have the ability to shop at a larger grocery store and to make choices about their food procurement. This feeling is evidenced by the following statement, which was made by a 39-year-old female participant upon initially receiving her loan, "So many people. I have no money. It makes me sad when I go to the grocery store because I see many things that I cannot buy.” This woman referenced her initial inability to feed her children upon beginning with the Mentors program, and then expressed the following, five months after receiving her loan, "We used to only eat instant noodles and eggs ... now we eat vegetables like lumpiang togue (egg rolls with vegetables and meat) and monggo (a type of bean)”.

Our interview data illustrate that participants' food procurement options, and therefore their sense of empowerment and self-worth, increased the longer they participated in the Mentors microlending program.

Although this particular finding is quite straightforward, our nutritional data tells a more nuanced story. Although our 24-h diet recall data illustrate that participants are achieving certain nutritional successes as a consequence of participating in the Mentors Program, there are some other deleterious, prestige-related aspects of their diet that seem to be related directly to the amount of disposable income that participants have on hand.

\section{Nutritional Successes}

Participants who just enrolled in the Mentors microlending program (Group 1a) had an average caloric intake below $2000 \mathrm{kcals} /$ day, whereas participants who had been in the program for two or more years (Group 2) managed to have an average caloric intake above $2000 \mathrm{kcals} /$ day (Table 2). This difference between groups serves as an indication that participation in the microlending program can lead to achievement of a higher level of overall food security as it relates to both food access and utilization (SDG 2). When asked about her food consumption changes since beginning the microlending program, one mother reported, "Yes, my [food consumption] changed a lot because before we only sometimes ate porridge and we really struggled. But now I have sent my kids to school and they graduated. And, we eat what we want now.” According to another 48-year-old woman, "From the time I got the loan from Mentors Philippines, we were able to have merianda (midafternoon snack) and we were also able to add more variety to our diet." Our 24-h diet recall data also indicated that not only were participants able to increase their caloric intake, but they 
simultaneously were able to diversity their diets as well as to increase their micronutrient consumption.

To reduce the likelihood of acquiring a diet-related NCD, daily requirements of micronutrient consumption must be met. Our data shows that upon arrival in the microlending program, most participants (Group 1a) were severely malnourished in terms of their micronutrient intake, with average intake levels being half the recommended daily value for nearly all micronutrients (Table 2).

Measuring participants' micronutrient intake again after three months of being in the Mentors program (see differences between Group 1a and 1b) highlights another interesting trend. On average, participants' intake of calories and both macro- and micronutrients actually decreased after the first three months of participation in the microlending program. Our interview data support this finding. Many participants indicated the overwhelming amount of stress, lack of time, and new information that consumed the first three months after joining the microlending program.

However, the individuals who were able to overcome these difficult first few months did manage to see positive nutritional outcomes after two years of being in the microlending program (see Table 2, Group 2 for exact figures), as evidenced by the fact that they were able to consume a higher amount of all micronutrients in comparison to those who just began the microlending program. As a 35-year-old female participant explained, "Before we only cooked canned foods, like sardines, for ulam (main dish) but after I received my loans, I can now buy chicken and pork.” A sufficient level of micronutrient consumption is beneficial to participants' health in numerous ways. Not only do micronutrients help the body with numerous functions such as properly regulating metabolism, increasing bone density, and strengthening the immune system, but proper micronutrient intake also improves concentration and the body's ability to absorb new information [38].

There are three specific micronutrient successes to highlight, the first of which is the average vitamin C intake among Group 2 participants. Although all participant groups managed to consume above RDI levels, those in Group 2, on average, were able to consume more than double the RDI for Vitamin C. This is paramount in reducing NCD risk because vitamin $\mathrm{C}$ is necessary for the synthesis of collagen, a major organic component of bone. Healthy synthesis of collagen in this research population (e.g., 99\% female) is of particular importance because appropriate collagen production serves to reduce the risk of osteoporosis.

The average vitamin A intake among the members of Groups $1 \mathrm{a}$ and $1 \mathrm{~b}$ was clearly below the RDI levels. However, Group 2's average vitamin A intake was nearly double the recommended level, which indicates a lower risk of this population developing NCDs caused by vitamin A deficiency such as night blindness [40]. Lastly, the average zinc intake among Group 1a was also slightly below the RDI levels, but Group 1b and Group 2 
reported average zinc intake above RDI levels. Zinc deficiency is most commonly associated with developmental issues in childhood [41].

Table 2. Differences in average daily intake between Group 1a, Group 1b, and Group 2.

\begin{tabular}{|c|c|c|c|c|}
\hline \multirow[t]{2}{*}{ Dietary Component } & \multirow[t]{2}{*}{ Recommended Daily Intake (RDI) * } & \multicolumn{3}{|c|}{ Average Daily Intake** } \\
\hline & & Group 1a & Group 1b $* * *$ & Group 2 \\
\hline Calories & 1610-1930 (kcal) & 1921.32 & 1606.91 & 2593.2 \\
\hline Carbohydrates & $265.38-366.88(\mathrm{~g})$ & 261.55 & 237.78 & 362.22 \\
\hline Protein & $62(\mathrm{~g})$ & 70.13 & 60.281 & 82.94 \\
\hline Fat & $32.80-65.80(\mathrm{~g})$ & 65.68 & 47.71 & 93.34 \\
\hline Vitamin A-RE & 600 (mcg) & 341.27 & 490.47 & 1079.66 \\
\hline Vitamin C & 60 (mg) & 112.09 & 66.33 & 145.93 \\
\hline Vitamin E & $10(\mathrm{mg})$ & 3.69 & 3.64 & 8.64 \\
\hline Vitamin $\mathrm{K}$ & 53 (mcg) & 25.37 & 15.81 & 31.56 \\
\hline Calcium & 750 (mg) & 359.26 & 292.06 & 556.11 \\
\hline Potassium & 3510 (mg) & 1392.01 & 1387.82 & 2496.82 \\
\hline Dietary Fiber & $20-25(\mathrm{~g})$ & 7.32 & 7.03 & 12.77 \\
\hline Iodine & 150 (mcg) & 37 & 33.89 & 38.62 \\
\hline Iron & 28 (mg) & 9.8 & 10.37 & 13.93 \\
\hline Zinc & 4.6 (mg) & 4.53 & 4.82 & 6.07 \\
\hline Omega 3 Fatty Acid & $0.5(\mathrm{~g})$ & 0.64 & 0.68 & 0.84 \\
\hline Sodium & 500 (mg) & 3431.89 & 2748.65 & 3979.23 \\
\hline Added Sugar & $\begin{array}{l}\text { Limit intake to }<10 \% \text { of total energy in } \\
\text { children and adults }<48.25 \text { (g) }\end{array}$ & 9.9 & 16.69 & 37 \\
\hline Alcohol $^{\dagger}$ & 14 (g of pure alcohol) $* * * *$ & 1.67 & 0.35 & 0.97 \\
\hline
\end{tabular}

* Values were calculated using the percent of the upper range value of recommended daily energy intake; for caloric intake, all ranges applicable to females aged 19-69 were included [39].

** The gray shaded cells indicate whether, on average, participants' micronutrient intake met or exceeded dietary guidelines.

*** Only 52\% of eligible research participants from Group 1B agreed to a second interview and 24-h diet recall, which significantly lowered the sample size of this follow-up group.

**** This RDI is based on United States figures because no such data was found for the Philippines.

$\dagger \quad$ According to our interview data, alcohol was not a major concern among participants. However, it must be noted that $99 \%$ of our interview population was female, and it was often brought to our attention that men consumed much more alcohol (and tobacco) than women did. We acknowledge that if we had interviewed more males, average alcohol intake and tobacco use likely would have been higher.

In addition to participants being able to increase their overall micronutrient density, our data illustrate that participants who had been with the Mentors program for two or more years consumed lower amounts of both alcohol and trans-fat than participants who just began the microloan program did, which also helps in reducing the risk of diet-related NCDs [42,43]. At the same time, Omega 3 consumption (which has been shown to have a range of health benefits including helping to reduce the risk of 
developing chronic heart disease) was higher among participants who had been in the microlending program longer. This combination of reducing trans-fat and alcohol consumption, while simultaneously increasing Omega 3 intake, has shown to have a positive impact on decreasing the risk of a range of NCDs, including diabetes and hypertension [44].

\section{Nutritional Concerns}

Although there were many nutritional successes, our 24-h diet recall data also revealed that not all dietary changes that Mentors participants made over time were positive. Microlending participants' average intake of added sugar and sodium was much higher among the participants in Group 2, which could be counteracting the aforementioned positive dietary intake changes. For example, whereas clients who just began working with the Mentors program consumed on average a mere $9.9 \mathrm{~g}$ of sugar per day, clients who had been in the program for two or more years were, on average, consuming $37 \mathrm{~g}$ of sugar per day. Although $37 \mathrm{~g}$ of sugar is still below the upper limit of suggested sugar intake [39], this finding may suggest an upward trend of sugar intake among participants who have been with the program for more than two years and by then had procured additional disposable income.

Perhaps of greatest nutritional concern is participants' average intake of sodium, especially given that in excess, high sodium can have negative implications on cardiovascular health. Among all participant groups, average intake was well above RDI (ranging from 5.5 times greater to 8 times higher than RDI). Interview data and ethnographic observations indicated that it is common to add three sources of sodium (i.e., salt, soy sauce, and MSG) when making traditional main dishes such as Chicken adobo and sinigang (a tamarin-based soup that usually contains fish and a variety of vegetables like okra, eggplant, green beans and unripe papaya).

According to our ethnographic data, many individuals ascribed prestige to these foods high in sugar and/or sodium. When we asked participants the question, "Would you buy different foods if you had access to more money?", $43 \%$ of those in Group 1a and $60 \%$ of those in Group 2 responded in the affirmative. Of those who responded yes, most indicated that they would buy foods that they do not usually have access to such as spaghetti, cakes, hot dogs, fast food, beef, shrimp, and other 'prestige' items high in both sugar and sodium. Many of the participants specifically indicated that they would purchase food at McDonalds or Jolly Bee (a local fast food chain) if their income increased.

These data reveal that as microlending participants continued to increase their economic stability, they had a choice to make in terms of what foods to purchase. However, without proper nutrition education, participants ran the risk of succumbing to the sugar- and salt-laden prestige foods that would again put them at higher risk of becoming malnourished, but in the form of over-nourishment rather than undernourishment. This risk directly contributes to the presence of the double 
burden of malnutrition, thereby hindering progress towards the achievement of SDG 2 .

\section{Limitations}

There are four major limitations to this study. The first is that due to time constraints, the authors were not able to track participants through the microlending program for a long period of time, and therefore did not have access to any longitudinal nutritional data that would capture any long-term dietary behavior changes that might have been associated with participation in the microlending program. To assess whether microlending participants experienced any dietary intake changes after three months of participation in the microlending program, we included Group $1 \mathrm{~b}$. However, only 52\% of eligible research participants from Group $1 \mathrm{~b}$ agreed to a second interview and 24-h diet recall, which significantly reduced the sample size of this follow-up group. This sample size reduction is this study's second limitation. When asked why they could not participate, most participants in Group 1b cited their increased stress levels and their additional business workload as the two primary reasons. The third limitation of this study is sample bias. Group 2 only consisted of participants who were still actively engaged in the Mentors Program after two years. This way of constituting Group 2 might have introduced a selection bias because the participants who dropped out of the program before then are not included in this sub-sample. The fourth major limitation is that this study was largely ethnographic. The authors did not perform any significance tests with the nutritional outcomes data gathered via Food Processor and Fitness Software. Therefore, there is a possibility that the differences in the nutritional outcomes for Group 1a and Group 2 could be due to random variability. Our qualitative data do support our nutritional findings, however.

\section{DISCUSSION}

\section{The Need for Nutrition Education}

In order to help gauge whether a microlending program would be an appropriate avenue for nutrition education, we asked all participants if they had interest in learning more about nutrition as a component of the microlending program. In response, 97\% of Group 1 participants and 77\% of Group 2 participants expressed interest. Participants were excited at the prospect of learning more about nutrition, with two women remarking, "Yes, for my children, grandchildren and also my family", and, "Yes, so that I will know what foods are nutritious, especially since I have kids now. So, I would like to know what foods are healthy." These comments indicate that female microlending participants often desire nutrition education for the benefit of not only themselves, but their children. This sentiment mirrors the findings of two recently conducted studies that show that female participants experienced positive nutritional outcomes due to 
microlending participation. The first found that they were more successful than men in maintaining quality diets in their households [45], and the second concluded that food expenditures increased significantly for women microlending clients after participation in a microlending program [46].

According to our interviews, "high blood" (Filipino slang for hypertension) is perceived by many to be extremely common and is often cited as the source of adverse health outcomes (i.e., if someone faints and/or has a seizure). However, how to reduce one's risk of hypertension and/or other diet-related NCDs is relatively unknown. This lack of knowledge was revealed by our research. Most microlending participants did not understand how to make positive dietary changes such as how to reduce their fat, sodium and added sugar intake, with many individuals not even realizing that they were consuming too much sodium. While one woman remarked, "It is really hard to know which foods are best for me since I have high blood [pressure]," another stated that, "When it comes to food, we just eat what we want.... right now, we eat what is most delicious, but we do not know what is most nutritious. I have high blood [pressure] and all I know is that I'm not supposed to eat fatty foods...”. These remarks are a good reflection of the overall uncertainty that participants had regarding evidence-based nutritional information.

Our ethnographic data are consistent with the findings from the recent WHO 2017 NCD Progress Report, which stated that the Philippines has implemented neither policies on salt/sodium content and consumption nor policies related to reducing saturated fatty acids and trans-fat [4]. Particularly as participants increase their economic wellbeing and access to disposable income, proper education about the health risks of consuming these foods in excess becomes paramount.

However, even though our data illustrate that microlending participants do often experience a shift in their diets as they progress throughout the microlending program, these dietary changes are not always positive. To counter this trend, microlending organizations could be more direct and intentional about incorporating nutrition education into their curriculum. A formally developed nutritional education program may not only prove to be an effective way to teach participants how to identify nutrient-dense foods high in micronutrients, but it could include lesson plans about how to shop economically, ways in which to reduce high-prestige additives like sugar and salt, while drawing the connection between diet, overweight/obesity, diet-related NCDs, wellbeing and productivity. Research shows that rotating savings and credit organizations (such as microlending) that rely on social pressures to ensure that payments are met are also effective in assisting participants to manage their self-control problems such as encouraging individuals to save money rather than spending it on luxury goods [47]. This finding further supports that the social pressure component of the microlending environment can be beneficial in terms of participants encouraging one 
another to make healthy food choices after they receive more nutritionrelated education.

Our data affirm what numerous scholars have recently stated regarding the need to further explore the effectiveness of incorporating health education trainings into microfinance platforms in terms of both health behavior change and health status [48]. However, our research highlights the need to further consider (a) the importance of nutritional information and (b) the proper timing of when in the microlending process individuals will be most attuned to the health-related information to increase the likelihood of material absorption. Although our data suggest that those participants who are first joining the Mentors microlending program (like those in Groups 1a and 1b) are most likely too preoccupied with the stresses of launching their businesses to comprehend additional nutritional information, and that those individuals further along in the program who have managed to stabilize their businesses (like those in Group 2) might be at a better place to receive and absorb nutrition-related information, more research needs to be conducted on the ideal time to introduce nutritional information into a microlending program for optimal material absorption and behavior change.

The infusion of more nutrition-related curricula into Filipino-based microlending organizations could not only help to accomplish the aforementioned WHO 2017 Philippines-specific nutritional initiatives, but also could assist microlending participants to lower their risk of developing another form of malnutrition as they acquire more disposable income (helping to achieve SDG 2), thereby additionally lowering their risk for developing a future diet-related NCD.

\section{CONCLUSIONS AND IMPLICATIONS}

Our interview data show that after two or more years of being enrolled in the Mentors International microlending program, participants were more likely to increase their income (SDG 1), to be able to send their children and grandchildren to school (SDG 4), to secure more stable housing (SDG 11), to increase their caloric intake and diet diversity (SDG 2) and to feel more empowered (SDG 3). Although many of the economicrelated successes are known byproducts of the microlending model, this research resulted in two relatively novel key findings. The first is that there is evidence of both positive and negative nutritional impacts that result from participation in a microlending program. The second is that microlending programs are well positioned to serve as an avenue for nutrition-related information dissemination, but most likely only after participants have been with the program for a certain amount of time.

Too often when public health practitioners attempt to provide nutritional information to low-income populations, there is a more pressing short-term need (i.e., financial and housing security) that takes priority over increasing nutritional knowledge (which was often cited by 
our research participants as a long-term need). Our data suggest, however, that because microlending provides a structured framework within which to achieve these two aforementioned short-term needs, it could also be utilized as an avenue to disseminate nutritional information. Further research should investigate the optimal timing of providing nutritional education to microfinance participants.

Not only could a well-timed nutritional education program assist microlending participants in making more informed nutritional food choices, but it also could prove effective in saving participants money and long-term burden by avoiding the future management of their own malnutrition and the consequential increased risk of developing a dietrelated NCD. Although we recommend that future research should aim to assess the efficacy of microlending-embedded nutritional training in increasing both the nutritional outcomes and nutritional status of microlending program participants, we do believe that this model could be used both to help to counter the uptick in the double burden of malnutrition in the Philippines and ultimately to increase the chance of achieving SDG 2 on a global scale.

\section{SUPPLEMENTARY MATERIALS}

The supplementary materials on the English and Tagalog translations of the semi-structured interview and the 24-h diet recall instruments are available online at https://doi.org/10.20900/jsr20200011.

\section{AUTHOR CONTRIBUTIONS}

MG and TL designed the study and formed the partnership with Mentors International. TL collected the data in the Philippines while EC oversaw the local logistics and MG consulted remotely. MG and TL performed data input and analysis, while all three authors prepared the manuscript.

\section{CONFLICTS OF INTEREST}

The authors declare that there is no conflict of interest.

\section{FUNDING}

The Utah State University Small Enterprise Education and Development (SEED) Program paid TL's living expenses while in the Philippines. Additionally, Mentors International provided funds to employ a translator for the duration of the data collection.

\section{ACKNOWLEDGMENTS}

The authors would like to extend their sincere gratitude to Mentors International, the Utah State SEED program, to Nathan McCellan and to all of the staff at the Mentors Philippines office for their financial and logistic support throughout the duration of this project. A very special thank you 
is in order for Mr. Christopher Ian Sumangil. Without his assistance in recruiting participants, scheduling interviews, and providing translation, this project would not have been possible. We also would like to thank the Department of Social Work, Sociology, and Anthropology at Utah State University for providing lab space for data entry and analysis, and the three anonymous reviewers who provided pivotal and enriching suggestions on an earlier draft of this manuscript.

\section{REFERENCES}

1. About the sustainable development goals. United Nations 2019. Available from: https://www.un.org/sustainabledevelopment/sustainable-development-goals/. Accessed 2019 Sep 15.

2. Sustainable Development Goal 2: Health. World Health Organization 2016. Available from: https://www.un.org/sustainabledevelopment/hunger/. Accessed 2019 Nov 10.

3. Duante CA, Canag JLQ, Patalen CF, Austria REG, Acuin CCS. Factors Associated with Overweight and Obesity among Adults 20.0 Years and Over: Results from the 2013 National Nutrition Survey, Philippines. Philipp J Sci. 2019;148(1):720.

4. Philipines Nutrition Profile: Global Nutrition Report 2019. Available from: https://globalnutritionreport.org/resources/nutrition-profiles/asia/southeastern-asia/philippines/\#profile. Accessed 2019 Sep 3.

5. Kolčić I. Double burden of malnutrition: A silent driver of double burden of disease in low-and middle-income countries. J Glob Health. 2012;2(2):020303.

6. Albataineh SR, Badran EF, Tayyem RF. Overweight and Obesity in Childhood: Dietary, Biochemical, Inflammatory and Lifestyle Risk Factors. Obesity Med. 2019;15:100112.

7. Bahreynian M, Qorbani M, Khaniabadi BM, Motlagh ME, Safari O, Asayesh H, et al. Association between obesity and parental weight status in children and adolescents. J Clin Res Pediatr Endocrin. 2017;9(2):11.

8. Mozaffarian D, Fahimi S, Singh GM, Micha R, Khatibzadeh S, Engell RE, et al. Global sodium consumption and death from cardiovascular causes. N Engl J Med. 2014;371(7):624-34.

9. Srour B, Fezeu LK, Kesse-Guyot E, Allès B, Méjean C, Andrianasolo RM, et al. Ultra-processed food intake and risk of cardiovascular disease: prospective cohort study (NutriNet-Santé). BMJ. 2019;365:1451.

10. Hartley L, Igbinedion E, Holmes J, Flowers N, Thorogood M, Clarke A, et al. Increased consumption of fruit and vegetables for the primary prevention of cardiovascular diseases. Cochrane Database Syst Rev. 2013;6:CD009874.

11. Dans A, Ng N, Varghese C, Tai ES, Firestone R, Bonita R. The rise of chronic non-communicable diseases in southeast Asia: time for action. Lancet. 2011;377:680-9. doi: 10.1016/s0140-6736(10)61506-1

12. Noncommunicable Diseases Progress Monitor, 2017. Geneva: World Health Organization. 2017. Available from: https://www.who.int/nmh/publications/ ncd-progress-monitor-2017/en/. Accessed 2019 Sep 25. . 
13. NCD Alliance. NCDs \& Sustainable Human Development. NCD Alliance. Available from: https://ncdalliance.org/why-ncds/NCDs Sustainable Human Development. Accessed 2019 Sep 23.

14. Philippines embraces efforts to step up cardiovascular disease care. World Health Organization. 2017. Available from: https://www.who.int/newsroom/feature-stories/detail/philippines-embraces-efforts-to-step-upcardiovascular-disease-care. Accessed 2018 Jun 23.

15. 2nd National Nutrition Summit: 8th National Nutrition Survey. Manila (Philippines): Food and Nutrition Research Institute, Department of Science and Technology; 2014. Available from: http://122.53.86.125/NNS/8thNNS.pdf. Accessed 2018 Jun 10.

16. Microfinance Barometer 2017: global trends of the sector... BNP Paribas. Available from: https://group.bnpparibas/en/news/microfinance-barometer2017-global-trends-sector. Accessed 2018 Nov 10.

17. Korth M, Stewart R, Van Rooyen C, De Wet T. Microfinance: development intervention or just another bank? J Agrarian Change. 2012;12(4):575-86.

18. Bauchet J, Marshall C, Starita L, Thomas J, Yalouris A. Latest findings from randomized evaluations of microfinance. Washington, DC (US): Consultative Group to Assist the Poor; 2011.

19. Samer S, Majid I, Rizal S, Muhamad M, Sarah-Halim, Rashid N. The Impact of Microfinance on Poverty Reduction: Empirical Evidence from Malaysian Perspective. Procedia Soc Behav Sci. 2015;195:721-8. doi: $10.1016 /$ j.sbspro.2015.06.343

20. Van Rooyen C, Stewart R, De Wet T. The impact of microfinance in subSaharan Africa: a systematic review of the evidence. World Dev. 2012;40(11):2249-62.

21. Meyer RL. Microfinance, poverty alleviation and improving food security: Implications for India. In: Food Security and Environmental Quality in the Developing World. Boca Raton (FL, US): CRC Press; 2010.

22. DeLoach SB, Lamanna E. Measuring the impact of microfinance on child health outcomes in Indonesia. World Dev. 2011;39(10):1808-19.

23. Karlan D, Thuysbaert B, Gray B. Credit with health education in Benin: a cluster randomized trial examining impacts on knowledge and behavior. Am J Trop Med Hyg. 2017;96(2):501-10.

24. De La Cruz N, Crookston B, Gray B, Alder S, Dearden K. Microfinance against malaria: impact of Freedom from Hunger's malaria education when delivered by rural banks in Ghana. Trans $\mathrm{R}$ Soc Trop Med Hyg. 2009;103(12):1229-36.

25. Rosenberg M, Jules R, Luetke M, Kianersi S, Nelson E, Jean-Louis F. Health Education Training Embedded in a Microfinance Platform Associated with Safer Sexual Behavior in Haitian Women. AIDS Behav. 2019;23(9):2375-85.

26. Isangula K. Improving women and family's health through integrated microfinance, health education and promotion in rural areas. J Sustain Dev. 2012;5(5):76.

27. Hamad R, Fernald LC. Microcredit participation and nutrition outcomes among women in Peru. J Epidemiol Community Health. 2012;66(6):e1. 
28. Dhungana BR, Singh JK, Acharya D, Gautam S, Paudyal P. Perceived Usefulness of a Microfinance intervention on health awareness and Practices in Nepal. Front Public Health. 2016;3:289.

29. Leatherman S, Metcalfe M, Geissler K, Dunford C. Integrating microfinance and health strategies: examining the evidence to inform policy and practice. Health Policy Plan. 2011;27(2):85-101.

30. Castell GS, Serra-Majem L, Ribas-Barba L. What and how much do we eat? 24hour dietary recall method. Nutr Hosp. 2015;31(3):46-8.

31. Sun Y, Roth DL, Ritchie CS, Burgio KL, Locher JL. Reliability and predictive validity of energy intake measures from the 24-hour dietary recalls of homebound older adults. J Am Diet Assoc. 2010;110(5):773-8.

32. Jonnalagadda SS, Mitchell DC, Smiciklas-Wright H, Meaker KB, Van Heel N, Karmally W, et al. Accuracy of energy intake data estimated by a multiplepass, 24-hour dietary recall technique. J Am Diet Assoc. 2000;100(3):303-11.

33. Assessment and Analysis Services. NutritionQuest 2019. Available from: https://nutritionquest.com/assessment/. Accessed 2019 Dec 18.

34. Bazzano LA, He J, Ogden LG, Loria CM, Vupputuri S, Myers L, et al. Agreement on nutrient intake between the databases of the First National Health and Nutrition Examination Survey and the ESHA Food Processor. Am J Epidemiol. 2002;156(1):78-85.

35. Clayton ZS, Fusco E, Schreiber L, Carpenter JN, Hooshmand S, Hong MY, et al. Snack selection influences glucose metabolism, antioxidant capacity and cholesterol in healthy overweight adults: A randomized parallel arm trial. Nutr Res. 2019;65:89-98.

36. Gómez-Martínez MA, Castillo-Martínez L, Velázquez-Aguilar C, VergaraCastañeda A, del Pilar Milke-García M, Orea-Tejeda A. Cross-sectional study of dietary fatty acid intake and its association to high blood pressure in a group of mexican adolescents. Rev Mex Endocrinol Metab Nutr. 2017;4:58-64.

37. Ali HI, Al Dhaheri AS, Elmi F, Ng SW, Zaghloul S, Ohuma EO. Water and Beverage Consumption among a Nationally Representative Sample of Children and Adolescents in the United Arab Emirates. Nutrients. 2019;11(9):2110.

38. Gómez-Pinilla F. Brain foods: the effects of nutrients on brain function. Nat Rev Neurosci. 2008;9(7):568.

39. Food and Nutrition Research Institute, Department of Science and Technology. Philippines. 2015. Available from: http://www.fnri.dost.gov.ph/images/ sources/PDRI-Tables.pdf. Accessed 2018 Jun 10.

40. Campagnoli TR, Smiddy WE. Vitamin A Deficiency. In: Manual of Retinal Diseases. Cham (Switzerland): Springer; 2016. p. 611-4.

41. Hambidge M. Human zinc deficiency. J Nutr. 2000;130(5):1344S-9S.

42. Ezzati M, Riboli E. Behavioral and dietary risk factors for noncommunicable diseases. N Engl J Med. 2013;369(10):954-64.

43. Beaglehole R, Bonita R, Horton R, Adams C, Alleyne G, Asaria P, et al. Priority actions for the non-communicable disease crisis. Lancet. 2011;377(9775):1438-47. 
44. Grocke MU, Haddix McKay K. Like Mother, Like Child? Understanding Transitions in Diet, Health, and Nutrition in Humla, Nepal. Stud Nepali Hist Soc. 2016;21(2):305-31.

45. Doocy S, Teferra S, Norell D, Burnham G. Credit program outcomes: coping capacity and nutritional status in the food insecure context of Ethiopia. Soc Sci Med. 2005;60(10):2371-82.

46. Dupas P, Robinson J. Savings constraints and microenterprise development: Evidence from a field experiment in Kenya. Cambridge (MA, US): National Bureau of Economic Research; 2008. NBER Working Paper No. 14693.

47. Ambec S, Treich N. Roscas as financial agreements to cope with self-control problems. J Dev Econ. 2007;82(1):120-37.

48. Lorenzetti LM, Leatherman S, Flax VL. Evaluating the effect of integrated microfinance and health interventions: an updated review of the evidence. Health Policy Plan. 2017;32(5):732-56.

How to cite this article:

Grocke MU, Light T, Collado EK. Using Microlending to Achieve SDG 2: A Qualitative Exploration of the NutritionRelated Impacts of Microlending Participation in Manila, Philippines. J Sustain Res. 2020;2(2):e200011. https://doi.org/10.20900/jsr20200011 